\title{
EFEITO DE DIFERENTES LÂMINAS DE IRRIGAÇÃO SOBRE A POPULAÇÃO DE Meloidogyne javanica E A PRODUTIVIDADE DE BANANEIRA NO NORTE DE MINAS GERAIS
}

\author{
REGINACÁSSIA FERREIRARIBEIRO ${ }^{2}$, CRISTIANE CORREACOSTA ${ }^{3}$, \\ ADELICAAPARECIDAXAVIER ${ }^{3}$, FLÁVIO PIMENTADE FIGUEIREDO ${ }^{4}$, \\ FLÁVIO GONÇALVES OLIVEIRA ${ }^{4}$, VICENTEPAULOCAMPOS ${ }^{5}$, \\ CLAUDIA REGINA DIAS-ARIEIRA ${ }^{6}$, EDSON HYIDU MIZOBUTSI $^{2}$
}

RESUMO - O presente trabalho teve por objetivo avaliar o efeito de diferentes lâminas de irrigação (100; $125 ; 150$ e $175 \%$ ), determinadas pela evapotranspiração de referência do tanque classe A, sobre a população de Meloidogyne javanica no solo, e sobre a produtividade e número de dias necessários para a floração e a colheita da bananeira Prata-Anã, no norte de Minas Gerais. Verificou-se que o número de juvenis de segundo estádio de $M$. javanica aumentou com o aumento das lâminas de irrigação com pico máximo em $118 \%$ da evapotranspiração do tanque classe A (ETtca) e que as lâminas de 125; 150 e $175 \%$ da ETtca proporcionaram produtividade da bananeira $\left(\mathrm{kg} \mathrm{ha}^{-1}\right)$ significativamente superior à lâmina de $100 \%$. No entanto, não afetou o número de dias para a floração e para a colheita da bananeira.

Termos para indexação: Musa spp., irrigação, nematóide das galhas.

\section{EFFECT OF DIFFERENT LEVELS OF IRRIGATION ON POPULATION OF Meloidogyne javanica AND BANANA PRODUCTIVITY IN NORTH OF MINAS GERAIS}

\begin{abstract}
The present work aimed to assess in the field the effect of irrigation different levels (100\%, $125 \%, 150 \%$ and $175 \%$ ) determined by evapotranspiration from the tank class A (ETtca), on the population of Meloidogyne javanica in the soil, banana productivity and number of days needs for flowering and yield of Prata-Anã cultivar of banana on the North of Minas Gerais state, Brazil. The number of second stage juveniles of $M$. javanica increased reaching the maximum $\mathrm{J} 2$ level at $118 \%$ of ETtca. The irrigation levels, 125,150 and $175 \%$ ETtca increased the banana productity in $\mathrm{kg} / \mathrm{ha}^{-1}$ significantly as compared to $100 \%$ level. However, no effect was observed on the number of days for flowering and for harvesting of Prata-Anã banana.
\end{abstract}

Index terms: Root-knot nematodes, Musa spp., irrigation.

\section{INTRODUÇÃO}

A banana é uma das frutas mais consumidas no mundo. É explorada na maioria dos países tropicais e subtropicais e desempenha importante papel socioeconômico (Cordeiro et al., 1995). Minas Gerais é o segundo Estado produtor, vindo atrás de São Paulo, Bahia, Pará e Santa Catarina (Agrianual, 2005). No norte de Minas, cerca de 8.000 ha, $67 \%$ da área irrigada, são cultivados atualmente com banana predominantemente do Grupo Prata (Portal da Fruticultura, 2007).

A bananeira, planta tipicamente tropical, exige calor constante e elevada umidade. Responde, linearmente, à quantidade de água no solo e à transpiração (Coelho, 2001). No entanto, não suporta inundações que durem mais que três dias, nem tampouco déficit hídrico. O norte de Minas é uma região com sérias limitações para o cultivo da bananeira devido à pequena quantidade de chuvas. No norte de Minas, normalmente, as plantações de

\footnotetext{
1(Trabalho 079-08). Recebido em: 02-04-2008. Aceito para publicação em: 19-09-2008.

${ }^{2}$ DSc., Professor de Educação Superior, Universidade Estadual de Montes Claros - regina.ribeiro@ unimontes.br - Bolsista da FAPEMIG. Rua Reinaldo Viana 2630, 39440-000, Janaúba - MG.

${ }^{3}$ Engenheira Agrônoma pela UNIMONTES

${ }^{4}$ Professor UFMG - Montes Claros - MG, 39570-000.

${ }^{5}$ Professor titular. Departamento de Fitopatologia, UFLA. Lavras - MG, 37200-000 - vpcampos@ufla.br

${ }^{6}$ Professor AdjuntoUniversidade Estadual de Maringá, Umuarama-PR, 87507-190, cdiasariera@bol.com.br
} 
banana são irrigadas de acordo com a máxima demanda evapotranspirométrica. No entanto, resultados obtidos por Figueiredo (2002), utilizando diferentes lâminas de irrigação em bananais irrigados de Jaíba-MG, mostraram que tal prática resulta em excesso de água para a cultura e, conseqüentemente, acarreta aumento dos gastos com água e energia elétrica.

Outro fator de extrema importância para a cultura da bananeira é o correto manejo de fitonematóides. De acordo com Sasser \& Freckman (1987), no mundo todo, a redução na produção de bananas, devido a fitonematoides, é de 19,7\%. Destes, destacam-se no norte de Minas os nematoides de galhas Meloidogyne spp. As estimativas de perdas causadas por Meloidogyne spp., em banana no Brasil são em média de $8 \%$ (Costa, 2000). Cofcewicz et al. (2001), em levantamento realizado em solos de bananais nos Estados de Pernambuco, Bahia, Minas Gerais, São Paulo, Santa Catarina e Rio Grande do Sul, detectaram presença de $M$. javanica e $M$. incognita em 58 e $34 \%$ das amostras, respectivamente. De acordo com estudo no período de 1999 a 2001, realizado por Dias \& Ribeiro Júnior (2001) em bananais do norte de Minas, houve aumento acentuado nas populações de Meloidogyne quando comparado com outros fitonematoides como Radopholus similis, Helicotylenchus spp. , Pratylenchus spp. e Rotylenchulus reniformis. Os danos causados aos cultivos de bananeira são proporcionais ao aumento das populações de Meloidogyne (Davide \& Marasigan, 1992; Patel et al., 1996; Costa et al., 1998). Estudando a flutuação populacional de $M$. incognita, em bananal da cv. Nanica, na região de Petrolândia (Pernambuco), Costa et al. (1997) constataram que altas populações do nematóide provocavam o retardamento do desenvolvimento dos perfilhos, redução do tamanho e do peso dos cachos, atraso na maturação, amarelecimento, declínio e até a morte das plantas.

Vários fatores, como temperatura, umidade, pH e textura de solo, influenciam na duração do ciclo de vida das espécies de Meloidogyne. Ambos, o excesso de água, por induzir condição anaeróbia no solo (déficit de oxigênio), e a falta por facilitar a dessecação do solo (déficit hídrico) contribuem para reduzir as populações de Meloidogyne (Charchar, 1995, 1999). Segundo Bridge (1987), o uso de irrigação favorece a população de nematóides, por propiciar condições constantes de umidade no solo. Vários trabalhos têm demonstrado que os níveis de irrigação, utilizando diferentes níveis de água, afetam o fator de reprodução de Meloidogyne, em diferentes culturas, bem como a reação de resistência das plantas aos nematóides (Chaves et al., 2003; Charchar et al., 2005).

Dessa forma, o presente trabalho teve por objetivo avaliar o efeito de diferentes lâminas de irrigação, em banana 'Prata-Anã', sobre a população de Meloidogyne javanica, e na produtividade da cultura.

\section{MATERIAL E MÉTODOS}

O ensaio foi conduzido em bananal da cultivar Prata-Anã, em pomar localizado na área experimental da UNIMONTES - Câmpus de Janaúba (MG), e com infestação homogênea de $M$. javanica. O solo no qual o ensaio foi montado, tem capacidade de campo $19 \%$, e ponto de murcha permanente $7,5 \%$, a densidade aparente é de $1,77 \mathrm{~g} / \mathrm{cm}^{3}$, a classificação textural do solo é areia franca. $\mathrm{O}$ ensaio foi montado em blocos ao acaso, com quatro tratamentos (quatro lâminas de irrigação: 100; 125; 150 e $175 \%$ de evapotranspiração de referência do tanque classe A) e cinco repetições. Utilizou-se o sistema de irrigação localizada por microaspersão, com aspersores com vazão de $80 \mathrm{~L} / \mathrm{h}$ e pressão de 200 $\mathrm{KPa}$. O manejo da irrigação foi realizado mantendose um turno de rega de 2 dias. Cada lâmina de irrigação foi aplicada em duas fileiras de plantas com 30 plantas. A testemunha recebeu irrigação uma vez por semana e teve a função de quebra-vento.

A avaliação das populações de $M$. javanica no solo foi realizada mensalmente, por dez meses (julho/ 2002 a abril/2003). A variação das temperaturas médias, máximas e mínimas, no período, foi de 30,5 (julho de 2002 ) $-35,3^{\circ} \mathrm{C}$ (outubro de 2002) e 16,1 (agosto de 2002 ) $-20,7^{\circ} \mathrm{C}$ (janeiro de 2003), e a precipitação média mensal variou de zero (agosto de 2002) a $337 \mathrm{~mm}$ (dezembro de 2002). As amostras de solo foram coletadas a $30 \mathrm{~cm}$ de profundidade e $20 \mathrm{~cm}$ de distância do pseudocaule em 10 plantas (família composta por mãe, filha e neta). Retiraramse quatro subamostras nos quatro pontos cardeais ao redor de cada família, compondo-se uma amostra composta. Após acondicionamento em sacos plásticos, devidamente etiquetados, as amostras foram levadas ao laboratório de Fitopatologia/ Nematologia da UNIMONTES, para extração dos nematóides do solo por meio da técnica de Jenkins (1964). A contagem dos nematoides foi realizada em câmara de Peters com auxílio de microscópio óptico.

Os resultados das médias da população de juvenis de segundo estádio de $M$. javanica foram submetidos à análise de variância e análise de regressão. 
Para a avaliação das características agronômicas, foram utilizadas 10 plantas-mãe para cada parcela, referente às lâminas de água, totalizando-se 200 plantas. As plantas da testemunha não foram avaliadas com relação às características agronômicas, em função de o nível de água fornecido ser inviável para a produção da bananeira. As características agronômicas avaliadas foram: número de dias decorridos do plantio à colheita, número de pencas por cacho e produtividade $\left(\mathrm{kg} \mathrm{ha}^{-1}\right)$.

\section{RESULTADOS E DISCUSSÃO}

A análise de variância do ensaio revelou que houve efeito das lâminas de água empregadas na irrigação de bananeira Prata-Anã sobre a população de $M$. javanica e sobre a produtividade da bananeira $(\mathrm{P} \leq 0,05)$. Os resultados do efeito das diferentes lâminas de irrigação com relação ao número médio de juvenis de segundo estádio por $100 \mathrm{~cm}^{3}$ de solo nos meses avaliados estão apresentados na Figura 1. Observa-se pelos resultados da análise de regressão que, com o aumento da lâmina de água, houve aumento significativo da população de $M$. javanica. O pico máximo do número de juvenis de segundo estádio do nematóide, cerca de 1.718 , por $100 \mathrm{~cm}^{3}$ de solo ocorreu com uma lâmina de irrigação de aproximadamente $118 \%$ da ETtca. Provavelmente, essa foi a condição que ofereceu melhores condições de sobrevivência com aeração suficiente sem, contudo, eliminar o filme de água necessário à movimentação dos nematóides no solo e à eclosão dos juvenis dos ovos. A partir da lâmina de $118 \%$ da ETtca, houve redução da população do nematóide, o que pode ser explicado pelo aumento do suprimento de água e, conseqüentemente, menor aeração. De acordo com Norton (1979), a umidade do solo regula a quantidade de aeração. Isto pode ter afetado a movimentação dos juvenis, além de induzir o solo a uma condição de anaerobiose, o que desfavorece os nematóides fitoparasitas por serem organismos aeróbios. Segundo Baxter \& Blake (1969), o desenvolvimento, a eclosão e a mobilidade de juvenis de $M$. javanica aumentam com o aumento da concentração de oxigênio. Vários autores têm demonstrado que a anoxia afeta a oviposição e a reprodução de nematoides (Cooper et al., 1970; Van Gundy et al., 1968; Prot \& Van Gundy, 1981; Wallace, 1971). A testemunha foi o tratamento que proporcionou multiplicação de $M$. javanica inferior às diferentes lâminas de irrigação com uma população média observada de 643 juvenis por 100 $\mathrm{cm}^{3}$ de solo. Este resultado era esperado, visto que tais parcelas apresentaram déficit hídrico. Isto pode ter interferido na eclosão e/ou movimentação de juvenis do segundo estádio, fato observado por Baxter \& Blake (1969). De acordo com Wallace (1959), quando ocorre déficit hídrico, o filme de água necessário à locomoção do nematóide torna-se muito fino, ocasionando um aumento da força coesiva entre o nematóide e as partículas do solo, aumentando assim a resistência ao movimento. Chaves et al. (2003), testando diferentes níveis diários de água na condução de bananeira, obtiveram resultados variáveis em relação aos diferentes clones de bananeira a $M$. javanica. Os autores verificaram para o clone Grande Naine 34 que, com o aumento das lâminas de água, houve um decréscimo na reação de resistência das plantas a $M$. javanica, enquanto para o clone Pacovan 47 não houve influência das lâminas de água sobre a resistência a $M$. javanica. Charchar et al. (2005) testaram várias lâminas de irrigação, em diferentes cultivares de ervilha nas condições de cerrado, com relação aos efeitos sobre a população de $M$. incognita, raça 1 e a produtividade de grãos. Verificaram para as oito cultivares de ervilha testadas que as lâminas de água de 156 e 177 mm provocaram redução de até $60 \%$, nos fatores de reprodução do nematóide, em relação às lâminas de 239; 311; 395 e $479 \mathrm{~mm}$.

Para a produtividade da planta-mãe não houve ajuste de modelos lineares, assim as médias foram analisadas pelo teste de Tukey, a 5\% (Tabela 1). Observou-se que os tratamentos $125 \%$ e $175 \%$ da ETtca não diferiram entre si (16.232 kg.ha ${ }^{-1}$ e 15.065 $\mathrm{kg} . \mathrm{ha}^{-1}$, respectivamente), mas foram significativamente superiores ao tratamento $100 \%$ da ETtca (11.968 kg.ha-1). A lâmina de $125 \%$ da ETtca proporcionou aumento significativo na produtividade de 4.264 kg.ha ${ }^{-1}$ em relação à lâmina de $100 \%$ da ETtca. Esperava-se que, no tratamento $150 \%$ da ETtca, fosse obtida média superior à verificada para a lâmina de $175 \%$ da ETtca, já que esta última lâmina, provavelmente, é uma quantidade excessiva de água para a bananeira 'Prata-Anã'. Entretanto, observouse que as parcelas referentes ao tratamento de $150 \%$ da ETtca estiveram expostas ao vento, que deve ter contribuído para reduzir o excesso de água. Confrontando os resultados aqui obtidos com os encontrados por Figueiredo (2002), parece que o ponto de máxima produtividade se encontra entre $120 \%$ e $125 \%$ de reposição de água, em relação à evapotranspiração de referência. Não houve efeito das lâminas de irrigação sobre o número de pencas por cacho nem sobre o número de dias entre o plantio e a colheita.

Apesar de os tratamentos relativos às lâminas 
$125 \%, 150 \%$ e $175 \%$ da ETtca não terem diferido entre si com relação à produtividade, recomenda-se o tratamento de $125 \%$ da ETtca pelo fato de o mesmo propiciar economia de água e energia elétrica.

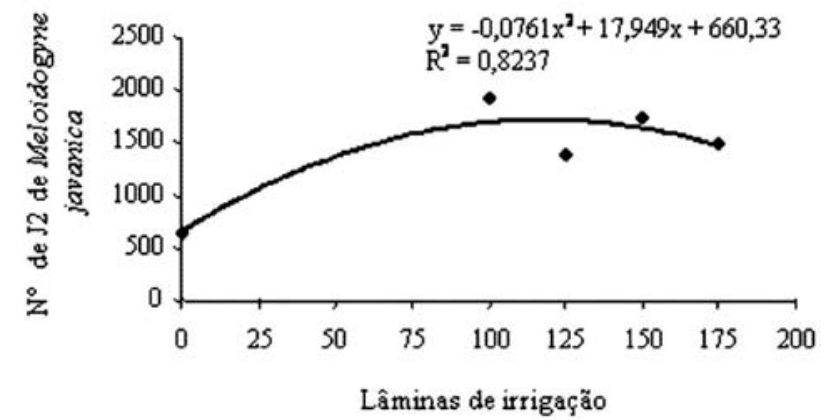

FIGURA 1- Média mensal do número de juvenis de segundo estádio de Meloidogyne javanica (J2)/100 cc de solo em bananeira irrigada com diferentes lâminas de irrigação: 0 (Rua sem irrigação), 100; 125; 150 e $175 \%$ da evaporação do tanque classe A, em 10 meses.

TABELA 1- Número de pencas por cacho (NPC), período compreendido do plantio à colheita (NDPC) e produtividade da planta-mãe da bananeira 'Prata-Anã', em função das lâminas de irrigação.

\begin{tabular}{lccc}
\hline Tratamentos & NPC & NDPC (dias) & Produtividade $\left(\mathbf{k g ~ h a ́}^{\mathbf{1}}\right)$ \\
\hline $100 \%$ ETtca & $8,60 \mathrm{a}$ & $399 \mathrm{a}$ & $11968 \mathrm{~b}$ \\
$125 \%$ ETtca & $8,58 \mathrm{a}$ & $394 \mathrm{a}$ & $16232 \mathrm{a}$ \\
$150 \%$ ETtca & $8,53 \mathrm{a}$ & $379 \mathrm{a}$ & $14036 \mathrm{ab}$ \\
$175 \%$ ETtca & $8,10 \mathrm{a}$ & $376 \mathrm{a}$ & $15065 \mathrm{a}$ \\
\hline
\end{tabular}

Médias seguidas pela mesma letra não diferem significativamente entre si, pelo teste de Tukey, a $5 \%$ de probabilidade.

\section{CONCLUSÕES}

1-As lâminas de irrigação 125; 150 e $175 \%$ da evapotranspiração do tanque classe A são as que proporcionam maior produtividade da bananeira.

2-Não há efeito das diferentes lâminas de irrigação sobre o número de dias necessários à floração e à colheita.

3-O número de juvenis de segundo estádio de $M$. javanica aumenta com o aumento das lâminas de irrigação, com pico máximo em $118 \%$ da evapotranspiração do tanque classe A.

\section{AGRADECIMENTOS}

À Fundação de Amparo à Pesquisa do Estado de Minas Gerais - FAPEMIG, pela concessão da bolsa de Incentivo à Pesquisa e ao Desenvolvimento Tecnológico.

\section{REFERÊNCIAS}

AGRIANUAL 2005: anuário da agricultura brasileira. São Paulo: FNP Consultoria \& Agroinformativos, 2005. p. 221-229.

BAXTER, R. I.; BLAKE, C. D. Oxygen and hatch of eggs and migration of larvae of Meloidogyne javanica. Annals of Applied Biology, Wellesbourne, v. 63, p. 191-203, 1969.

BRIDGE, J. Control strategies in subsistence agriculture. In: BROW, R.H; KERRY,R.B. Principles and practice of nematode control in crops. Sidney: Academic Press, 1987. p.389- 418.

CHARCHAR, J. M.; MAROUELLI, W. A.; GIORDANO, L.B.; ARAGÃO, F. A. S. Reprodução de Meloidogyne incognita raça 1 e produtividade de cultivares de ervilha sob diferentes lâminas de água. Pesquisa Agropecuária Brasileira, Brasília, vol.40, n.10, p.989-995. 2005. 
CHAVES, A. M.; CARRIJO, O. A.; TENENTE, R. C. V.; SILVA NETO, S. P. Efeito de diferentes níveis de irrigação no desenvolvimento e na reação de clones de bananeira (Musa spp.) infectados com Meloidogyne javanica (Treub, 1885) Chitwood, 1949. In: SIMPÓSIO BRASILEIRO SOBRE BANANICULTURA. WORKSHP DO GENOMA MUSA, 5., 2003, Paracatu-MG. Anais... Cruz das Almas-BA: Gráfica e Editora Nova Civilização, 2003. p.187-188.

COFCEWICZ, E.T.; CARNEIRO, R. M. D. G.; QUÉNÉHÉRVÉ, P. ;AUGUSTIN, E.; FARIA, J. L. C. Ocorrência de Meloidogyne spp. em áreas produtoras de banana no Brasil. In: CONGRESSO BRASILEIRO DE NEMATOLOGIA, 23., 2001. Anais... Piracicaba: FAEF, 2001. p. 112.

COOPER, A. F.; VAN GUNDY, S. D.; STOLZY, L. H. Nematode reproduction in environments of flutuacting aeration. Journal of Nematology, Lakeland, v.2, p.182-188, 1970.

COSTA, D. da C. Nematoses em banana e abacaxi no Brasil: danos e manejo. CONGRESSO BRASILEIRO DE NEMATOLOGIA, 22., 2000, Uberlândia Anais... p.50-58.

COSTA, D. DA C.; SILVA; de O.S.; ALVES, F.R.; SANTOS ,A. do C. Avaliação de danos e perdas à bananeira cv. Nanica causadas por Meloidogyne incognita na região de Petrolândia- PE. Nematologia Brasileira, Piraciacba, v. 21, n. 1, p.21, 1997.

COSTA, D. da C.; SILVA, S. de O. ; ALVES, F. R. Reação de genótipos de bananeiras (Musa spp.) a Radopholus similis e Meloidogyne incognita. Nematologia Brasileira, Piracicaba, v. 22, n. 2, p.4957, 1998.

COELHO, E. F.; OLIVEIRA, S. L.; COSTA, E. L. Irrigação da bananeira. In: SIMPÓSIO NORTE MINEIRO SOBRE A CULTURA DA BANANA, 1. 2001, Nova Porteirinha. Anais... Montes Claros: Editora Unimontes, 2001. p.91-101.

DAVIDE, R.G.; MARASIGAN, L. Q. Yeld loss assessment and evaluation of resistance of banana cultivars to the nematodes Radopholus similis and Meloidogyne incognita. In: DAVIDE, R. G. Studies on nematodes affecting bananas in the Philippines. Los Banõs, Laguna: Philippine Agriculture and Resources Research Foundation, 1992. p. 17-37; 7993.
DIAS, M. S. C.; RIBEIRO JÚNIOR, P. M. Nematóides na bananicultura. In: SIMPÓSIO NORTE MINEIRO SOBREACULTURADABANANA, 1., 2002. Anais... Montes Claros: Editora Unimontes, 2001. p.168-179.

FIGUEIREDO, F. P., OLIVEIRA, F. G.; PEREIRA, M. C. T.; CUNHA, L. M. V.; PEREIRA, L.S. Efeitos de diferentes lâminas de irrigação na produtividade da bananeira "Prata - Anã “ cultivada no norte de Minas Gerais. In: SEMINÁRIO DE PESQUISA E PÓSGRADUAÇÃO, 3., SEMINÁRIO DE INICIAÇÃO CIENTÍFICA, 1., 2002. Anais... Montes Claros: Ed. Unimontes, 2022. p. 117.

JENKINS, W. R. A rapid centrifugal- flotation technique for separating nematodes from soil. Plant Disease Reporter, St Paul, v. 48, n. 9, p. 692, 1964.

NORTON, D. C. Relationship of physical and chemical factors to populations of plant-parasitic nematodes. Annual Review of Phytopatology, Palo Alto, v.17, p: 279-299, 1979.

PATEL, B.A.; VYAS, R.V.; PATEL. D. J.; PATEL, R. S. Susceptibility of banana cultivars to root-knot nematodes (Meloidogyne spp). Infomusa, Montpellier, v. 5, p. 26-27, 1996.

PORTAl DA FRUticultura. Portal da fruticultura no Norte de Minas: informações de mercado. Disponível em: <http:// www.abanorte.com.br/mercado $>$. Acesso em: 10 abr. 2007.

PROT, J. C.; VAN GUNDY, S. D. Effect of soil texture and the day component on migration of Meloidogyne incógnita juveniles. Journal of Nematology, Lakeland, v. 13, p. 213-217, 1981.

SASSER, J. N.; FRECKMAN, D. W. A world perspective on nematology: the role of the society. In: VEECH, J. A.; DICKSON, D. W. Vistas on Nematology: a commemoration of the twenty-fifth anniversary of the society of nematologist. DeLeon Springs: Society of Nematologist, 1987. p. 158-165.

SIKORA, R. A. Nematode of banana, plantains and abaca. In: M. Luc; R. A SIKORA, J. BRIDGE. Plant parasitic nematodes in subtropical and tropical agriculture. Wallinford: CAB International, 1990. p. 431-460. 
VAN GUNDY, S. D.; McELROY, F. D.; COOPER, A. F.; STOLZY, L. H. Influence of soil temperature, irrigation and aeration on Hemicycliophora arenaria. Soil Science, Baltimore, v.106, p. 270-274, 1968.

WALLACE, H. R. Abiotic influences in the soil environment. In: ZUCKERMAN, B. W.; MAI, W. F.;
ROHDE, R. A. Plant parasitic nematodes. New York: Academic Press, 1971. 345p.

WALLACE, H. R. The movement of eelworms in water films. Annals of Applied Biology, Wellesbourne, v. 47, p. 366-370, 1959. 